\title{
A breakthrough in direct conversion of methane to oxygenates under mild conditions
}

\author{
Yan-Xia Zhao ${ }^{1,2}$ and Sheng-Gui $\mathrm{He}^{1,2,3^{*}}$
}

Methane is an attractive $\mathrm{C} 1$ resource for production of value-added chemicals. The current industrial utilization of methane involves indirect route via preliminary oxidation to syngas (a mixture of $\mathrm{CO}$ and $\mathrm{H}_{2}$ ) that can be converted to desired products [1]. Such two-stage process is energy-intensive. Considerable efforts have been devoted to developing catalytic processes that can efficiently and directly transform methane through oxidative or non-oxidative pathways $[2,3]$. Since the pioneering work of methane dehydroaromatization under nonoxidative conditions in 1993 [4], a variety of catalysts based on metal ions (Mn, Fe, $\mathrm{Zn}, \mathrm{Mo}, \mathrm{W}$, etc.) dispersed on zeolites have been tested to improve the efficiency and product selectivity of non-oxidative methane conversion [3]. Recently, lattice-confined single-iron catalyst embedded in a silica matrix has been developed to convert methane exclusively to ethylene and aromatics with total hydrocarbon selectivity exceeding $99 \%$ at methane conversion of $48.1 \%$ [5]. However, the catalysis requires an extremely high operating temperature of $1090^{\circ} \mathrm{C}$. Oxidative conversion of methane to oxygenates over heterogeneous transition metal oxide catalysts (typically $\mathrm{MoO}_{3}$ and $\mathrm{V}_{2} \mathrm{O}_{5}$ ) are also generally performed under high temperatures $\left(>350^{\circ} \mathrm{C}\right)[6,7]$. Although homogeneous metal (e.g., $\mathrm{Pt}, \mathrm{Pd}, \mathrm{Au}$, etc.) catalysis opened up the possibility of oxidizing methane at low temperatures $\left(0-220^{\circ} \mathrm{C}\right)$ with high selectivity [8], the commercial application is hampered by the need for highly corrosive or expensive chemicals and the difficulty in separation/recycling of the catalysts. The natural methane monooxygenases (MMOs) can selectively catalyze the transformation of methane to methanol at ambient conditions [9]. Attempts to artificially mimic the activity of MMOs at low temperatures have been made by encapsulating the active binuclear centers of $\mathrm{Cu}$ and $\mathrm{Fe}$, in a form analogous to MMOs, within the zeolite catalysts [10]. Nonetheless, those artificial catalysts are far from industrial application due to the low product yield $\left(<200 \mu \mathrm{mol} \mathrm{g}_{\text {cat }}{ }^{-1}\right)$.

Recently, Shan, Li, and Flytzani-Stephanopoulos at Tufts University in collaboration with their co-workers from Oak Ridge and Argonne National Laboratories reported an exciting discovery that the atomically dispersed rhodium catalysts on zeolite (ZSM-5) and titanium dioxide (titania) can catalyze the direct oxidation of methane to oxygenates (acetic acid and methanol) using oxygen and carbon monoxide at aqueous solution [11]. Furthermore, the catalysts can be operated at low temperature of $150^{\circ} \mathrm{C}$. The product yields of acetic acid over $0.5 \mathrm{wt} \% \mathrm{Rh}-\mathrm{ZSM}-5$ and methanol over $0.6 \mathrm{wt} \% \mathrm{Rh}-\mathrm{TiO}_{2}$ can reach $\sim 22,000 \mu \mathrm{mol} \mathrm{g}_{\text {cat }}{ }^{-1}$ and $\sim 230 \mu \mathrm{mol} \mathrm{g}_{\text {cat }}{ }^{-1}$, respectively. The product selectivity ranges from $60 \%$ to $100 \%$.

The meticulous performance test of the catalysts revealed that the product selectivity is oxygen-limited and acidity-sensitive. For Rh-ZSM-5 catalysts, the product selectivity of methanol and acetic acid increases significantly upon decreasing the partial pressure of oxygen $\left(p_{\mathrm{O}_{2}}, 4\right.$ bar $\rightarrow 2$ bar). When the $p_{\mathrm{O}_{2}}$ is lowered down to 0.5 bar, the highest acetic acid selectivity is achieved. The presence of Brønsted acid sites in zeolite can promote the selectivity for acetic acid [12]. The authors ingeniously designed the catalyst of Rh-Na-ZSM-5 with fewer Brønsted acid sites for comparison. It was found that the primary product can be tuned toward methanol. When the $\mathrm{Rh}-\mathrm{TiO}_{2}$ catalyst that lacks the acid sites of H-ZSM-5 is used, the sole product of methanol is identified. The formation of acetic acid thus requires the presence of Brønsted acid sites while the acid site is not essential for

\footnotetext{
${ }^{1}$ State Key Laboratory for Structural Chemistry of Unstable and Stable Species, Institute of Chemistry, Chinese Academy of Sciences, Beijing 100190, China

${ }^{2}$ Beijing National Laboratory for Molecular Sciences, CAS Research/Education Center of Excellence in Molecular Sciences, Beijing 100190, China

${ }^{3}$ University of Chinese Academy of Sciences, Beijing 100049, China

"Email: shengguihe@iccas.ac.cn
} 


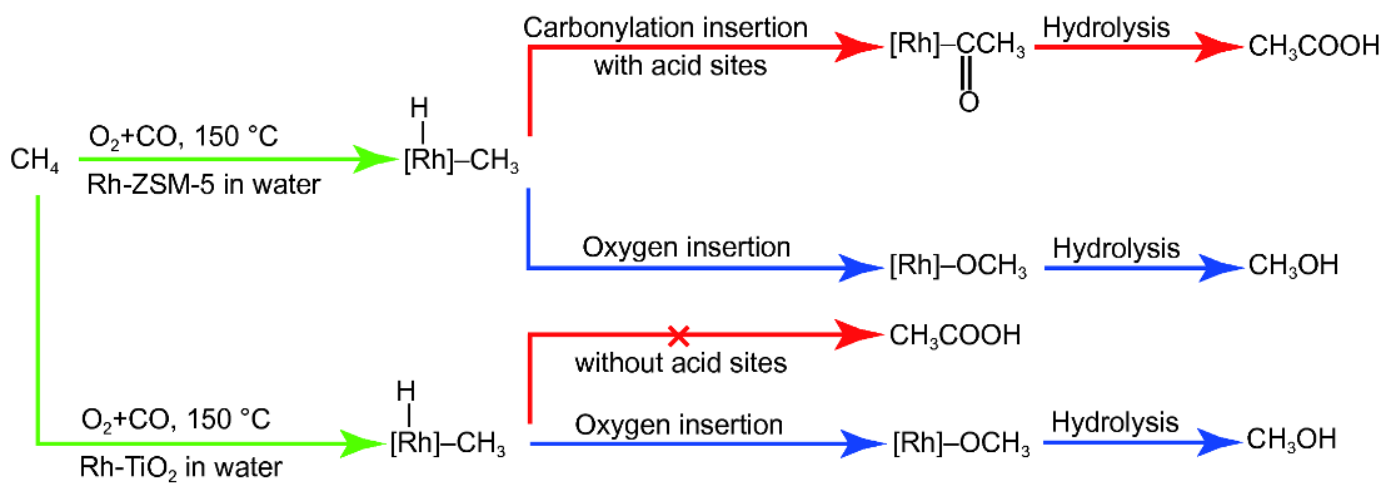

Figure 1 Proposed mechanisms for direct conversion of methane to acetic acid and methanol over supported mononuclear rhodium catralysts.

methanol production.

To uncover the superior catalytic activity of the catalysts, diverse morphological and spectroscopic characterizations have been performed for Rh-ZSM-5 to determine the dispersion state and valence state of rhodium. The authors concluded that the active sites are the isolated mononuclear rhodium cations [dominantly $\mathrm{Rh}^{\mathrm{I}}(\mathrm{CO})_{2}$ ] inside the zeolite micropores. Taking into account that no oxygenates are formed when the catalysts are exposed to the atmosphere with only $\left(\mathrm{CH}_{4}+\mathrm{CO}\right)$ or only $\left(\mathrm{CH}_{4}+\mathrm{O}_{2}\right)$, methane activation by $\mathrm{Rh}$ in the presence of $\mathrm{CO}$ and $\mathrm{O}_{2}$ has been proposed (Fig. 1).

The independent reaction pathways for the formation of acetic acid and methanol have been figured out relying on more experimental evidence. Isotope $\left({ }^{13} \mathrm{CO}\right)$ labeling measurements suggested that $\mathrm{CO}$ inserts directly into the $\mathrm{Rh}-\mathrm{CH}_{3}$ bond to form $\mathrm{Rh}-\mathrm{COCH}_{3}$ in the presence of acid sites in the Rh-ZSM-5 catalysts. The CO molecule may also act as a co-catalyst in the form of Rh-bonded CO ligand to promote the insertion of an oxygen atom into the $\mathrm{Rh}-\mathrm{CH}_{3}$ bond to form $\mathrm{Rh}-\mathrm{OCH}_{3}$. The formed $\mathrm{Rh}-$ $\mathrm{COCH}_{3}$ and $\mathrm{Rh}-\mathrm{OCH}_{3}$ can be further hydrolyzed to acetic acid and methanol, respectively (Fig. 1).

Although the exact mechanisms of methane activation and $\mathrm{Rh}-\mathrm{CH}_{3}$ functionalization remain unclear, this study has made a breakthrough in the direct oxidation of methane under mild conditions for production of valueadded chemicals. The crucial roles of $\mathrm{CO}$ molecule to facilitate catalytic methane conversion have been emphasized. The introduction of CO can lead to effective engineering of the geometric and electronic structures of the active metal centers, as reported in coordination chemistry, organometallic chemistry, and catalytic chemistry [13-16].

In the context of methane activation, a previous study has indicated that the dissociative CO-adsorption can tune down the spin density distribution on metal centers, which then promotes methane activation through oxidative addition [17]. The creative idea of introduction of alien molecules to promote catalytic processes can guide the design of new and more efficient catalysts for selective methane oxidation.

Received 27 December 2017; accepted 28 December 2017; published online 10 January 2018

1 Aasberg-Petersen K, Dybkjær I, Ovesen CV, et al. Natural gas to synthesis gas-catalysts and catalytic processes. J Nat Gas Sci Eng, 2011, 3: 423-459

2 Horn R, Schlögl R. Methane activation by heterogeneous catalysis. Catal Lett, 2015, 145: 23-39

3 Schwach P, Pan X, Bao X. Direct conversion of methane to valueadded chemicals over heterogeneous catalysts: challenges and prospects. Chem Rev, 2017, 117: 8497-8520

4 Wang L, Tao L, Xie M, et al. Dehydrogenation and aromatization of methane under non-oxidizing conditions. Catal Lett, 1993, 21: $35-41$

5 Guo X, Fang G, Li G, et al. Direct, nonoxidative conversion of methane to ethylene, aromatics, and hydrogen. Science, 2014, 344: 616-619

6 Tabata K, Teng Y, Takemoto T, et al. Activation of methane by oxygen and nitrogen oxides. Catal Rev, 2002, 44: 1-58

7 Olivos-Suarez AI, Szécsényi À, Hensen EJM, et al. Strategies for the direct catalytic valorization of methane using heterogeneous catalysis: challenges and opportunities. ACS Catal, 2016, 6: 2965-2981

8 Gunsalus NJ, Koppaka A, Park SH, et al. Homogeneous functionalization of methane. Chem Rev, 2017, 117: 8521-8573

9 Rosenzweig AC, Frederick CA, Lippard SJ, et al. Crystal structure of a bacterial non-haem iron hydroxylase thatcatalyses the biological oxidation of methane. Nature, 1993, 366: 537-543

10 Ravi M, Ranocchiari M, van Bokhoven JA. The direct catalytic oxidation of methane to methanol-a critical assessment. Angew Chem Int Ed, 2017, 56: 16464-16483

11 Shan J, Li M, Allard LF, et al. Mild oxidation of methane to methanol or acetic acid on supported isolated rhodium catalysts. 
Nature, 2017, 551: 605-608

12 Narsimhan K, Michaelis VK, Mathies G, et al. Methane to acetic acid over $\mathrm{Cu}$-exchanged zeolites: mechanistic insights from a sitespecific carbonylation reaction. J Am Chem Soc, 2015, 137: 18251832

13 Ding S, Hall MB. The rich structural chemistry displayed by the carbon monoxide as a ligand to metal complexes. Struct Bond, 2016, 169: 199-248

14 Serna P, Gates BC. Molecular metal catalysts on supports: organometallic chemistry meets surface science. Acc Chem Res, 2014, 47: $2612-2620$
15 Wang YG, Yoon Y, Glezakou VA, et al. The role of reducible oxide-metal cluster charge transfer in catalytic processes: new insights on the catalytic mechanism of $\mathrm{CO}$ oxidation on $\mathrm{Au} / \mathrm{TiO}_{2}$ from ab initio molecular dynamics. J Am Chem Soc, 2013, 135: 10673-10683

16 Yuan Z, Li XN, He SG. CO oxidation promoted by gold atoms loosely attached in $\mathrm{AuFeO}_{3}^{-}$cluster anions. J Phys Chem Lett, 2014, 5: 1585-1590

17 Liu QY, Ma JB, Li ZY, et al. Activation of methane promoted by adsorption of $\mathrm{CO}$ on $\mathrm{Mo}_{2} \mathrm{C}_{2}^{-}$cluster anions. Angew Chem Int Ed, 2016, 55: 5760-5764 